\title{
Associations between socioeconomic index and mortality in rural and urban small geographic areas of Catalonia, Spain: Ecological study
}

\author{
Caro-Mendivelso $\mathrm{J}^{* 1}$, Elorza-Ricart $\mathrm{JM}^{1}$, Hermosilla $\mathrm{E}^{1}$, Méndez-Boo L ${ }^{2}$, García-Gil $\mathrm{M}^{1,3}$, Prieto-Alhambra $\mathrm{D}^{1,4}$, \\ Medina $\mathrm{M}^{2}$ \\ ${ }^{1}$ Institut Universitari d'Investigació en Atenció Primària Jordi Gol (IDIAP Jordi Gol), Catalonia, Spain. \\ ${ }^{2}$ SISAP (Sistema d'Informació dels Serveis d'Atenció Primària), Institut Català de la Salut (ICS), Catalonia, Spain. \\ ${ }^{3}$ Translab Research Group, Department of Medical Sciences, School of Medicine, University of Girona, Catalonia, Spain. \\ ${ }^{4}$ Nuffield Department of Orthopaedics, Rheumatology and Musculoskeletal Sciences, University of Oxford, United Kingdom.
}

Received: August 20, 2015

DOI: $10.5430 /$ jer.v2n1p 80
Accepted: October 26, 2015

Online Published: November 4, 2015

\begin{abstract}
Objective: To analyse the association between MEDEA (Mortality in small areas of Spain and socioeconomic and environmental inequalities) index and mortality in urban and rural areas of Catalonia.

Methods: An ecological study based on the analysis of census section. The data source used for census section and variables to calculate the MEDEA index was the census (2001). Mortality data were obtained from System for the Development of Research in Primary Care (SIDIAP). The census sections were classified as rural or urban. The association between mortality and the socioeconomic index was analysed as categorical variable (quintiles). Poisson models were fitted to study the association between MEDEA index and mortality. Analysis was done with the STATA software, version 12.

Results: In January 2009, a total of 4,526,071 adults (> 14 years old) were assigned to ICS (Institut Català de la Salut ) primary healthcare centres. The identified population lived in 5,214 census sections out of a total of 5,222 existing areas, from which 4096 (78.5\%) were urban. The association between MEDEA quintiles and mortality was significant for urban areas excluding Barcelona: excess mortality was 5\% (IRR $=1.05$ IC 95\% 1.01-1.10), being higher in urban areas (IRR $=1.1195 \% \mathrm{CI} 1.08$ to 1.15 ) and even higher in Barcelona (IRR $=1.2495 \%$ CI 1.18 to 1.31 ). This association was not significant for rural areas (IRR = 0.95 CI 95\% 0.88-1.02).

Conclusions: Socioeconomic deprivation, measured with the MEDEA index, was related with an increase in total mortality in urban areas of Catalonia. In rural areas there was no association with mortality.
\end{abstract}

Key Words: Mortality, Deprivation index, Small areas, Rural areas, Urban areas, Electronic health record

\section{INTRODUCTION}

Health is influenced not only by individual characteristics, but also by social and environmental factors. In recent years, researchers have studied the ways in which the characteris- tics of an individual's area of residence have an impact on that person's health. ${ }^{[1,2]}$ Socio-demographic characteristics and socioeconomic status are related with mortality and with disease risk. ${ }^{[3-7]}$ In the eighties, Townsend developed the

\footnotetext{
* Correspondence: Caro-Mendivelso J, Project Coordinator; Email: jmcaro@gencat.cat; Address: Institut d'Investigació en Atenció Primària (IDIAP-Jordi Gol)Gran Via de les Corts Catalanes 587, àtic. 08007 Barcelona, Spain.
} 
concept of deprivation as a result of social inequalities, defined as "a state of observable disadvantage of an individual, family or group, related to the community, society or nation to which they belong". ${ }^{[8]}$ Indices to assess deprivation include both social and material dimensions. The concept of the deprivation of an area has been used to study the health impacts related to the socioeconomic aspects of a geographic location. ${ }^{[9]}$

Traditionally, there have been two different types of research on social inequalities and health: at the individual level or group level. Despite the strengths and limitations of both lines of research, many studies have suggested the usefulness of both approaches, both separately and as complementary efforts. The main limitation of studies at individual level is that data are often unavailable, leading to the use of ecological indicators for geographic areas. ${ }^{[10]}$ Various deprivation indices have been used, based on the available information for small geographic areas, such as a neighbourhood, census section or postal code. ${ }^{[6,7,9,11-13]}$ In the United Kingdom, the English Indices of Deprivation 2010 provide a measure of deprivation at small area level across England. ${ }^{[14]}$ In Spain, the relationship between socioeconomic inequalities and mortality has been studied using several indices of deprivation in small areas. ${ }^{[15-18]}$ One of the indices was developed within the framework of the MEDEA project (Mortalidad en áreas pequeñas Españolas y Desigualdades Socioeconómicas y Ambientales, or Mortality in small areas of Spain and socioeconomic and environmental inequalities [MEDEA]). The MEDEA index was used in 5 cities in Spain, using the census section as the unit of analysis and 2001 census data. Employment and education, the socioeconomic indicators that best explained the variability of the Standard Mortality Ratio (SMR) were selected for analysis. ${ }^{[9]}$ This index allows the study of associations between socioeconomic indicators and mortality for various cities at the level of the census section, ${ }^{[19]}$ it has been shown to differ by sex ${ }^{[20]}$ and size of city studied. ${ }^{[21]}$ Furthermore, it has been described that deprivation indices tend to be sensitive to differences between urban and rural areas. ${ }^{[22]}$ In Spain, use of the MEDEA index has not been analysed for rural areas to date.

In order to obtain a socioeconomic indicator to incorporate into the epidemiological databases, a review of literature was undertaken to evaluate the available indices. Of all those analysed, the MEDEA index was selected because it was developed in our setting (including the city of Barcelona), using data available from the census and easily applied to this analysis. In Catalonia, the clinical databases of the Catalan Institute of Health (Institut Català de la Salut, ICS) contain mortality information and although neither the census section nor socioeconomic information is recorded, home addresses

Published by Sciedu Press are available and can be cross-referenced to obtain the census section, from which the socioeconomic data can be inferred to analyse social inequalities. The ICS is the major provider of primary healthcare services, responsible for nearly $80 \%$ of the population (i.e., 5.8 million people).

The reason for doing this study is to test how the MEDEA index captures measures of deprivation in urban and rural settings that might impact on mortality, because it hadn't been used in rural areas before. The objective of this study was to carry out a small-area analysis of the associations between the MEDEA index and overall mortality in urban and rural areas of Catalonia.

\section{METHODS}

\subsection{Design and participants}

This was an ecological study based on an analysis of census section. The study population was all adults ( $>14$ years old) assigned to ICS primary healthcare centres in Catalonia $(\mathrm{n}=$ 4,526.071).

\subsection{Data sources}

The data source used for census section and variables to calculate the MEDEA index was the census. Mortality data were obtained from System for the Development of Research in Primary Care (SIDIAP) (www.sidiap.org).

\subsubsection{Census}

A demographic census of the entire population of Catalonia is undertaken every 10 years by Spain's national statistical institute (Instituto Nacional de Estadística); census data collected in 2001. Information is provided for census section that is an administrative territorial division to use in statistical operations. It's defined by population size criteria and delimits the territory accidents and geographic; the small size let the homogeneity of the houses that compose it. Furthermore, this information includes the five variables required to calculate the MEDEA index: 1) manual workers; 2) unemployed; 3) part-time workers; 4) under-educated (total); and 5) undereducated (young adults), using the weights corresponding to the values calculated for the city of Barcelona during the original MEDEA project. ${ }^{[9]}$ It is provided by the Statistical Institute of Catalonia (Idescat).

\subsubsection{SIDIAP}

It is a clinical database that uses data from the electronic health record system of the ICS in primary care (ECAP), and others complementary data sources, making available valid and reliable data for research on primary healthcare. The SIDIAP database contains individual patient information linked to a unique, anonymous identifier and covers 5.8 million individuals (80\% of the Catalan population and $10.2 \%$ 
of the total population of Spain) registered in 279 ICS primary healthcare teams. ${ }^{[23]}$ Mortality data were obtained from SIDIAP. For the purpose of the study, individuals were considered deceased if their death was recorded in the electronic health record between 1 January 2009 and 31 December 2012. The mortality data chosen was for 2009-2012 when the census data is from 2001 because more recent census was not available.

\subsection{Unit of analysis section}

The unit of analysis was the census section; SIDIAP compiled information from the ECAP and the census. SIDIAP data were linked to the census 2001 data.

Since ECAP did not contain the census section information needed to link the two data sources, an ad-hoc dictionary was created that mapped the home address free-text fields. This dictionary was then cross-referenced with the recorded addresses for ICS patients to obtain a relationship between the anonymised patient identifier and the corresponding census section, which was also stored as anonymised data.

\subsection{Classification of rural and urban areas}

Census sections were classified as rural or urban on the basis of the municipality to which they correspond. Each census section corresponds to rural or urban. A municipality with more than 10,000 inhabitants and a population density greater than $150 / \mathrm{km}^{2}$ was considered urban. ${ }^{[24]}$

\subsection{Analysis}

The MEDEA index was categorized in quintiles, with quintile 1 corresponding to the least deprived population and quintile 5, the most deprived.

All census sections were considered that had any population assigned to ICS primary healthcare centres, independently of their size and incidence of mortality. To analyse the association of the MEDEA index and mortality in the different geographic areas (total Catalonia, urban areas, city of Barcelona, urban areas other than Barcelona and rural areas), a Poisson regression model was used, inflated to zeros because the aggregated nature of data had a higher number of zeros that was inconsistent with the Poisson distributed. ${ }^{[26]}$ The association between MEDEA quintile and mortality was evaluated using age- and sex-adjusted, zero-inflated, Poisson regression modeling (IRR and 95\% CI) ${ }^{[26]}$.

In the analysis strategy, the incidence Rate Ratio (IRR) was calculated, taking the first quintile on the MEDEA index as the reference category and then adjustments were made for age and sex. The first quintile means the least deprived. Statistical significance was determined as $p<.05$. Analysis was done with the STATA software, version 12.

\section{Results}

In January 2009, a total of 4,526.071 adults (> 14 years old) were assigned to ICS primary healthcare centres. The census section (census data collected in 2001) could be identified for $96.7 \%$ of this population, establishing that $861.185(18.4 \%)$ of these patients lived in rural municipalities.

The study population was distributed in 5,214 census sections (of the total 5,222 in the 2001 census), of which 4,096 (78.5\%) were urban. In Catalonia as a whole, the median number of patients per section was 830 , with an interquartile range (IQR) of 1,116; the median was $875(\mathrm{IQR}=855)$ in urban areas, $691(\mathrm{IQR}=839)$ in Barcelona (city), $1056(\mathrm{IQR}$ $=880)$ in urban areas other than Barcelona, and $486(\mathrm{IQR}=$ $1,098)$ in rural areas.

The MEDEA index value calculated for each census section in all of Catalonia ranged from -1.92 to 5.27 , with a mean of 0.36 . In urban areas, the range was the same but the mean was 0.43 ; in rural areas, the range was -1.66 to 3.26 , with a mean of 0.17 .

In urban areas, both the percentage of women and the average age of the population decreased as the level of deprivation increased. In rural areas, the percentage of women followed the socioeconomic pattern of other geographic areas, but age remained stable across the quintiles of deprivation (see Table $1)$.

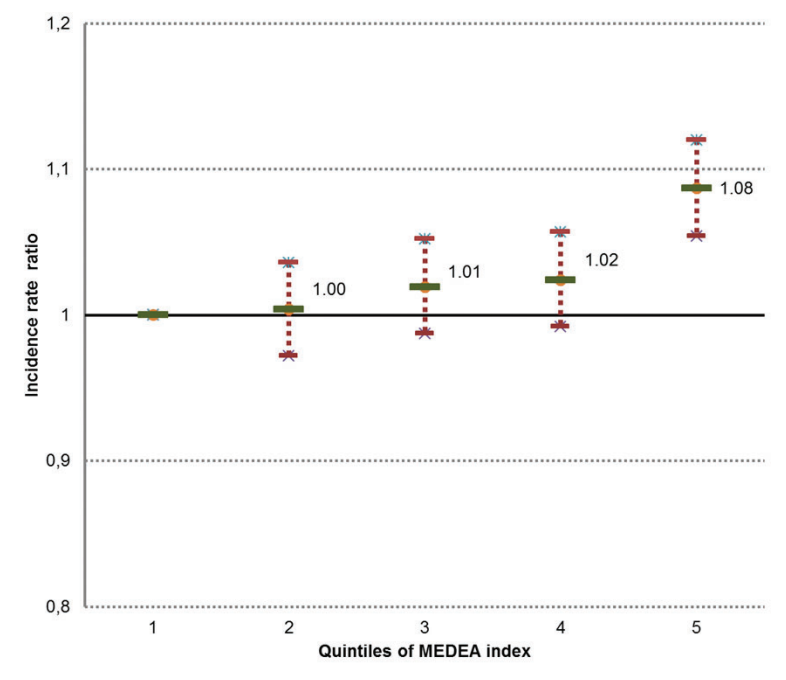

Figure 1. Mortality adjusted by age and sex, by quintiles of deprivation (MEDEA) for all of Catalonia

A study of the relationship between the MEDEA index categorized by quintiles and mortality showed an association between the index and mortality for Catalonia as a whole and for urban areas. In Catalonia overall, the quintile with the greatest deprivation had a mortality rate $8 \%$ higher than

ISSN 2377-9306 E-ISSN 2377-9330 
that of the quintile with the best socioeconomic conditions (IRR adjusted for age and sex $=1.08$ 95\% CI 1.05-1.12) (see Figure 1). In urban areas other than Barcelona, there was $5 \%$ excess mortality $(\mathrm{IRR}=1.0595 \%$ CI $1.01-1.10)$, being greater $(11 \%)$ in the group of all urban areas $($ IRR $=1.11$ 95\% CI 1.08-1.15) and even higher in the city of Barcelona, reaching $24 \%($ IRR $=1.2495 \% \mathrm{CI} 1.18-1.31)$. This relationship was not significant in the rural areas (IRR $=0.9595 \%$
CI 0.88-1.02) (see Figure 2).

\section{Discussion}

Greater socioeconomic deprivation, measured with the MEDEA index, was related with an increase in total mortality in urban areas of Catalonia, and especially in the city of Barcelona. On the other hand, no association was observed in rural areas.

Table 1. Demographics of census sections by geographical area and level of deprivation (quintiles of MEDEA index)

\begin{tabular}{|c|c|c|c|c|c|}
\hline Geographic area & MEDEA index (Quintiles) & Census sections (n) & Persons assigned (n) & Women (\%) & Age Mean (SD) \\
\hline & 1 & 541 & 283,637 & 54.4 & 47.8(19.3) \\
\hline Barcelona city & 2 & 360 & 255,646 & 53.4 & 47.1(19.1) \\
\hline (cs: 1491) & 3 & 226 & 166,580 & 52.6 & 47.3(19.2) \\
\hline \multirow[t]{3}{*}{ (n: 992021) } & 4 & 190 & 141,632 & 51.8 & $46.7(19.2)$ \\
\hline & 5 & 174 & 144,526 & 47.2 & 43.1(18.6) \\
\hline & 1 & 306 & 353,996 & 52.4 & $46.0(18.5)$ \\
\hline \multirow{5}{*}{$\begin{array}{l}\text { Other urban areas } \\
\text { (cs: 2605) } \\
\text { (n: 2709148) }\end{array}$} & 2 & 368 & 426,632 & 41.6 & $45.4(18.4)$ \\
\hline & 3 & 493 & 589,109 & 51.0 & $45.3(18.4)$ \\
\hline & 4 & 662 & 657,785 & 50.6 & $44.9(18.4)$ \\
\hline & 5 & 776 & 681,626 & 48.8 & $44.0(18.4)$ \\
\hline & 1 & 847 & 637,633 & 53.3 & $46.8(18.9)$ \\
\hline \multirow{5}{*}{$\begin{array}{l}\text { All urban areas } \\
\text { (cs: 4096) } \\
\text { (n: 3701169) }\end{array}$} & 2 & 728 & 582,278 & 52.2 & 46.0(18.7) \\
\hline & 3 & 719 & 755,689 & 51.4 & $45.7(18.6)$ \\
\hline & 4 & 852 & 799,417 & 50.8 & 45.3(18.6) \\
\hline & 5 & 950 & 826,152 & 48.5 & 43.8(18.5) \\
\hline & 1 & 196 & 129,710 & 50.5 & 47.1(18.8) \\
\hline \multirow{5}{*}{$\begin{array}{l}\text { Rural areas } \\
\text { (cs: 1118) } \\
\text { n: 824902) }\end{array}$} & 2 & 315 & 217,231 & 49.8 & 47.1(19.1) \\
\hline & 3 & 324 & 249,515 & 49.6 & 47.6(19.5) \\
\hline & 4 & 191 & 159,106 & 49.3 & $46.9(19.3)$ \\
\hline & 5 & 92 & 69,340 & 48.9 & 47.1(19.4) \\
\hline & 1 & 1,043 & 767,343 & 52.8 & 46.9(18.9) \\
\hline \multirow{4}{*}{$\begin{array}{l}\text { Catalonia } \\
\text { (cs: 5214) } \\
\text { (n: 4526071) }\end{array}$} & 2 & 1,043 & 899,509 & 51.7 & 46.3(18.8) \\
\hline & 3 & 1,043 & 1005,204 & 50.9 & 46.2(18.9) \\
\hline & 4 & 1,043 & 958,523 & 50.6 & 45.5(18.7) \\
\hline & 5 & 1,042 & 895,492 & 48.5 & 44.1(18.5) \\
\hline
\end{tabular}

Note. n: Persons assigned to primary care centers; cs: census section; MEDEA index quintils: 1 (least deprived) and 5 (most deprived);

$S D$ : standard deviation.

The values obtained for Barcelona in the original MEDEA project were applied to all of the census sections in Catalonia. To address the possible lack of validity of the values obtained in other urban areas or in rural areas, we considered the need to analyse the behaviour of the index in different small areas. In Spain, no previous study had analysed the MEDEA index in rural areas, and therefore we had no evidence for that setting. In other countries, socioeconomic indices have been designed to fit the setting, depending on the degree of Published by Sciedu Press urbanisation of the geographic area. ${ }^{[27,28]}$

As described in other studies, deprivation indices tend to be sensitive to differences between urban and rural areas; this is one of their main limitations in developing a common index. ${ }^{[22]}$ The original focus on material deprivation has generated standardized deprivation indicators for typical urban settings that are not applicable to rural areas. ${ }^{[27,29]}$ In the United Kingdom, for example, factors unique to rural areas 
have been identified that could be associated with rural deprivation: income (low salaries, high cost of living), type of work (long hours, vulnerable industries, limited transportation), type of housing (low quality, limited selection, high prices in some regions), lack of access to public services (public transit, healthcare services) and sociocultural characteristics (lack of confidence), tension between residents and non-residents, such as tourists and seasonal visitors). ${ }^{[28]}$ In rural Catalonia, geographical access to essential services could constitute an element of deprivation. ${ }^{[30]}$ Barnett identified unemployment as the most important indicator in urban areas, and level of income the best evidence of deprivation in rural areas. ${ }^{[27]}$
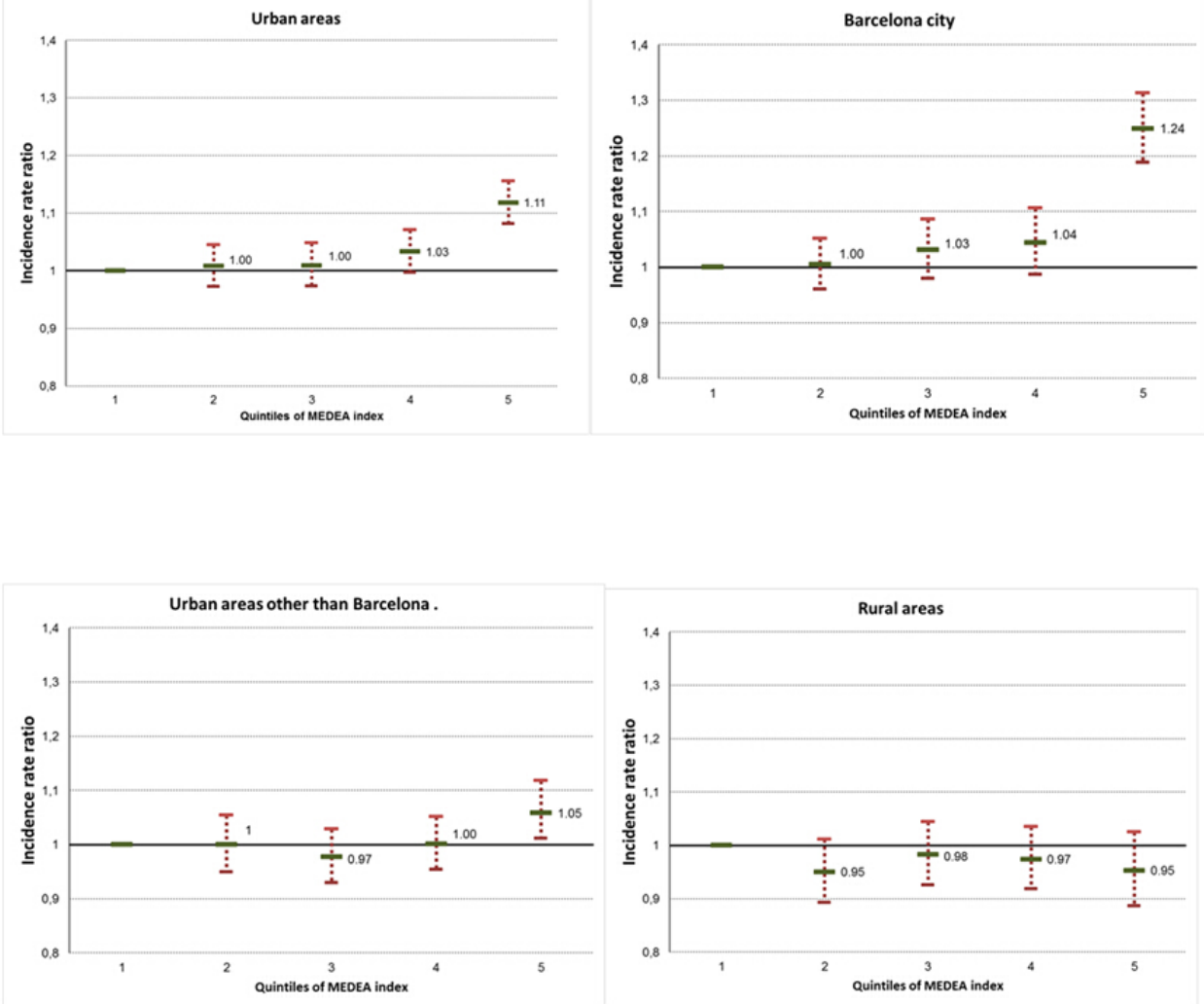

Figure 2. Mortality adjusted by age and sex, by quintiles of deprivation (MEDEA) for urban areas, Barcelona city, urban areas other than Barcelona and rural areas

In the case of the MEDEA index, the indicators used are those that best fit the five cities included in the original project. $^{[9]}$ Conceptually, the application of the MEDEA index appears to be appropriate for studies of urban areas, given the diversity of cities included in the original study. ${ }^{[19]}$ Nonetheless, it is to be expected, a priori, that it would not work in the same way in rural areas, as our study illustrated. This possibility was raised by the original MEDEA researchers, who considered that it might not be appropriate to use the same indicators in urban and rural settings. ${ }^{[9]}$ An indicator such as the proportion of manual labourers could behave very differently in urban and rural areas. In Barcelona, for example, agriculture is practically non-existent, but in interior rural areas it is much more evident. ${ }^{[24]}$ From our point of view, in rural areas where agriculture is the main economic activity the fact of working in this sector need not be associated with economic disadvantage. In urban areas, being a manual labourer is linked more to the industrial sector, with jobs that require lower qualifications and provide lower pay. For all these reasons, there may be a need to devise a specific index with indicators that are appropriate to the situation of this rural area.

With respect to the differences between areas of greater and lesser deprivation, if we compare our results in the city of Barcelona with those reported from other studies, the relationship between the MEDEA index and mortality was greater in the present study. ${ }^{[9]}$ This could be due to the difference in the time periods and the study population. On one hand, we did not include the entire population of Barcelona, limiting inclusion to those assigned to ICS primary healthcare centres; nonetheless, the sample can be considered representative be- 
cause it included an important percentage of the population in all socioeconomic strata. On the other hand, our study used mortality data for 2009-2012, while the Borrell study analysed 1996-2003. This could be explained by economic changes, such that deprivation could have had greater impact on mortality in recent years (2009-2012) than it did a few decades ago (1996-2003). ${ }^{[19]}$

Regarding of the 2001 census for the construction of an indicator in 2012, there is little variation in terms of the deprivation of geographic areas over the years. A study carried out in Scotland to compare the census of 1981 with 2001 found that $73 \%$ of the census sections maintained the same quintile or went up or down one level, while $2 \%$ of the sections shifted between the extreme quintiles. ${ }^{[31]}$

The primary strength of the present study is our use of the same unit of analysis (census section) as the MEDEA project, the greatest geographic disaggregation provided by the cen-

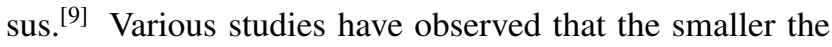
reference area, the more likely it is that the population will be homogeneous and possible differences in health status will be better detected, reducing the potential of ecological risk. ${ }^{[32]}$

One of the limitations of our study is that we did not use a mortality register. However, the electronic health records database that was used has been validated against the official mortality register, and the results were very reliable. The mortality information of ECAP records had a sensitivity of 98.6\% and specificity of $99.9 \%$ (Cross-sectional study of REGICOR deaths from 1995 to 2009 vs. SIDIAP 2011. Unpublished data). Therefore, cause of death is not available in SIDIAP. Therefore, although interesting, the authors were unable to characterise the effect of socio-economic status on different causes of death.

Some of the conceptual and methodological limitations con- sidered in previous studies must be considered when estimating deprivation in urban and rural areas, such as the heterogeneity of the population and level of standardisation. ${ }^{[22]}$

Although the MEDEA index has demonstrated its usefulness in urban areas, it is still necessary to develop an index that adapts to the specific context of rural areas. This would allow their inclusion in epidemiological studies with the relevant socioeconomic elements that otherwise cannot be analysed.

The results of the present study show, once again, the importance of socioeconomic factors to health status, ${ }^{[3]}$ a fact that should be incorporated into adjustments made in epidemiological analyses and health planning. Along these lines, recent data suggest that a distribution of healthcare costs inversely proportional to per capita income could have a positive impact on avoidable mortality associated with socioeconomic deprivation. ${ }^{[33]}$

\section{Conclusions}

The MEDEA index is associated with mortality in Barcelona and to a lesser extent to other urban areas. In rural areas there is no relationship. The main contribution of this study is to demonstrate the need to develop an index that suits rural areas. We studied the association between MEDEA index and mortality for different cities including Barcelona. The relevance of the study is the need of an index for measuring socioeconomic deprivation in rural areas.

\section{ACKNOWLEDGEMENTS}

The authors appreciate the support provided by the staff of SISAP (Sistema d'Informació dels Serveis d'Atenció Primària) and the assistance of the Public Health Agency of Barcelona in carrying out this project. We would also like to thank the Idescat for provided the census information and to thank Elaine Lilly, Ph.D., for English language revision.

\section{REFERENCES}

[1] Díez-Roux AV. Investigating neighborhood and area effects on health. Am J Public Health. 2001; 91: 1783-9. PMid:11684601 http://dx.doi.org/10.2105/AJPH.91.11.1783

[2] Díez-Roux AV. The study of group-level factors in epidemiology: Rethinking Variables, Study Designs, and Analytical Approaches. Epidemiol Rev. 2004; 26: 104-11. PMid:15234951 http://dx.d oi.org/10.1093/epirev/mxh006

[3] Puigpinós-Riera R, Marí-Dell'Olmo M, Gotsens M, et al. Cancer mortality inequalities in urban areas: a Bayesian small area analysis in Spanish cities. International Journal of Health Geographics. 2011; 10: 6. PMid:21232096 http://dx.doi .org/10.1186/147 6-072X-10-6

[4] Manrique-Garcia E, Sidorchuk A, Hallqvist J, et al. Socioeco- nomic position and incidence of acute myocardial infarction: a meta-analysis. J Epidemiol Community Health. 2011; 65: 301 9. PMid:20841371 http://dx.doi.org/10.1136/jech. 2009 .104075

[5] Fukuda Y, Nakamura K, Takehito T. Higher mortality in areas of lower socioeconomic position measured by a single index of deprivation in Japan. Public Health. 2007; 121: 163-73. PMid:17222876 http://dx.doi.org/10.1016/j.puhe.2006.10.015

[6] Padilla C, Lalloué B, Pies C, et al. An Ecological study to identify census blocks supporting a higher burden of disease: infant mortality in the lille metropolitan area, France. Matern Child Health J. 2014; 18: 171-9. PMid:23479336 http://dx.doi.org/10.1007/s10 995-013-1251-8

[7] Stringhini S, Dugravot A, Shipley M. Health behaviours, socioeco- 
nomic status, and mortality: Further Analyses of the British Whitehall II and the French GAZEL prospective Cohorts. PLoS Med. 2011; 8: e1000419. PMid:21364974 http://dx.doi.org/10.1371/j ournal.pmed. 1000419

[8] Townsend P, Phillimore P, Beattie A. Health and deprivation. Inequality and the North. London: Routledge. 1988.

[9] Domínguez-Berjón MF, Borrell C, Cano-Serral G, et al. Constructing a deprivation index based on census data in large Spanish cities (the MEDEA project). Gac Sanit. 2008; 22: 179-87. PMid:18579042

[10] Benach J, Borrell C, Chamizo H. Desigualdades sociales en mortalidad en áreas pequeñas. La Salud Pública y el futuro del Estado del Bienestar. Informe SESPAS. 1998.

[11] Rey G, Jougla E, Fouillet A, et al. Ecological association between a deprivation index and mortality in France over the period 1997 2001: variations with spatial scale, degree of urbanicity, age, gender and cause of death. BMC Public Health. 2009; 9: 33. PMid:19161613 http://dx.doi.org/10.1186/1471-2458-9-33)

[12] Pampalon R, Hamel D, Gamache P. Health inequalities in urban and rural Canada: comparing inequalities in survival according to an individual and area-based deprivation index. Health Place. 2010; 16: 416-20. PMid:20022551 http://dx.doi.org/10.1016/j.h ealthplace.2009.11.012

[13] Meijer M, Engholm G, Grittner U, et al. A socioeconomic deprivation index for small areas in Denmark. Scand J Public Health. 2013; 41: 560-9. PMid:23599378 http://dx.doi.org/10.1177/140 3494813483937

[14] McLennan D, Barnes H, Noble M, et al. The English indices of deprivation 2010. 2011. London: Department for Communities and Local Government. Available from: http://www. communities.gov.uk/publications/corpor ate/statistics/indices2010 [verifiedApri12015]

[15] Sánchez-Cantalejo C, Ocaña-Riola R, Fernández-Ajuria A. Deprivation index for small areas in Spain. Social Indicators Research. 2008; 89: 259-73. http://dx.doi.org/10.1007/s11205-007 $-9114-6$

[16] Ocaña-Riola R, Saurina C , Fernández-Ajuria A, et al. Area deprivation and mortality in the provincial capital cities of Andalusia and Catalonia (Spain). J Epidemiol Community Health. 2008; 62: 14752. PMid:18192603 http://dx.doi.org/10.1136/jech. 2006 .053280

[17] Benach J, Yasui Y, Borrell C, et al. Material deprivation and leading causes of death by gender: evidence from a nationwide small area study. J Epidemiol Community Health. 2001; 55: 239245. PMid:11238578 http://dx.doi.org/10.1136/jech.55.4 .239

[18] Domínguez-Berjón MF, Borrell C. Mortality and socioeconomic deprivation in the census tracts and districts of Barcelona. Gac Sanit. 2005; 19: 363-9. PMid:16242094

[19] Borrell C, Marí-Dell'Olmo M, Serral G, et al. Inequalities in mortality in small areas of eleven Spanish cities (the multicenter MEDEA project). Helath \& Place. 2010; 16: 703-711. http://dx.doi.org /10.1016/j.healthplace.2010.03.002
[20] Salcedo N, Saez M, Bragulat B, et al. Does the effect of gender modify the relationship between deprivation and mortality? BMC Public Health. 2012; 12: 574. PMid:22846597 http://dx.doi.o rg/10.1186/1471-2458-12-574

[21] Martínez-Beneito MA, Zurriaga O, Botella-Rocamora P, et al. Do socioeconomic inequalities in mortality vary between different Spanish cities? a pooled cross-sectional analysis. BMC Public Health. 2013; 13: 480. PMid:23679869 http://dx.doi .org/10.1186/1471-2 458-13-480

[22] Bertin M, Chevrier C, Pelé F, et al. Can a deprivation index be used legitimately over both urban and rural areas? Int J Health Geogr. 2014; 13: 22. PMid:24929662 http://dx.doi.org/10.1186/1 476-072X-13-22

[23] Bolíbar B, Fina F, Morros R, et al. SIDIAP database: electronic clinical records in primary care as a source of information for epidemiologic research. Med Clin (Barc). 2012; 138: 617-21. PMid:22444996 http://dx.doi.org/10.1016/j.medcli.2012.01.020

[24] Programa de desarrollo rural de Catalunya. Período de programación 2007-2013. Generalitat de Catalunya. Departament d'Agricultura, Ramaderia, Pesca, Alimentació i Medi Natural. Decisión C (2008) 702. Versión séptima, Mayo de 2011.

[25] Domínguez Amorós M, Monllor Rico N, Simó Solsona M. Món rural $\mathrm{i}$ joves. Realitat juvenil i polítiques de joventut als municipis rurals de Catalunya. 2010; Col·lecció Estudis, 31. Generalitat de Catalunya.

[26] Lambert D. Zero-inflated Poisson Regression, with an Application to Defects in Manufacturing. Technometrics. 1992; 34. http: //dx.doi.org/10.2307/1269547

[27] Barnett S, Roderick P, Martin D, et al. A multilevel analysis of the effects of rurality and social deprivation on premature limiting long term illness. J Epidemiol Community Health. 2001; 55: 44-51. PMid:11112950 http://dx.doi.org/10.1136/jech.55.1.44

[28] Gartner A, Farewell D, Roach P, et al. Rural/urban mortality differences in England and Wales and the effect of deprivation adjustment. Soc Sci Med. 2011; 72: 1685-1694. PMid:21524504 http://dx.doi.org/10.1016/j.socscimed.2011.03.017

[29] Farmer JC, Baird AG, Iversen L. Rural deprivation: reflecting reality. Br J Gen Pract. 2001; 51: 486-91. PMid:11407056

[30] Lerxtundi-Manterola A, Saurina C, Saez M, et al. Construcción de un índice de privación material para los municipios de la Región Sanitaria Girona. Estudios de economía aplicada. Asociación Internacional de Economía aplicada. 2005; 23: 331-353.

[31] Exeter D, Boyle P, Norman P. Deprivation (im) mobility and causespecific premature mortality in Scotland. Soc Sci Med. 2011; 72: 38997. PMid:21106285 http://dx.doi.org/10.1016/j.socscim ed. 2010.10 .009

[32] Krieger N. Overcoming the absence of socioeconomic data in medical records: validation and application of a census-based methodology. Am J Public Health. 1992; 82: 703-10. PMid:1566949 http://dx.doi.org/10.2105/AJPH.82.5.703

[33] Barr B, Bambra C, Whitehead M, et al. The impact of NHS resource allocation policy on health inequalities in England 2001-11: longitudinal ecological study. BMJ. 2014; 348: g3231. PMid:24865459 http://dx.doi.org/10.1136/bmj.g3231 